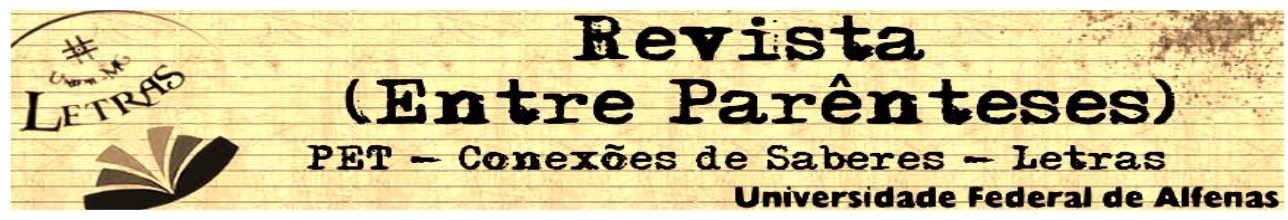

\title{
ANÁLISE DE CHARGES JORNALÍSTICAS
}

\author{
Graziela Christina de Oliveira ${ }^{1}$ \\ Faculdades Associadas de Uberaba (Fazu) \\ grazi.christina@terra.com.br
}

\begin{abstract}
Resumo: $O$ trabalho tem como objetivo investigar se os efeitos de sentido pretendidos pelas charges podem nos ajudar a compreender melhor os fatos e elaborar nossas opiniões. A pesquisa se justifica pela importância no entendimento de gêneros textuais diferentes que estão constantemente ao nosso redor. A metodologia é de natureza qualitativa e utiliza da Análise do Discurso para avaliar os elementos levantados em charges escolhidas apenas pelo conteúdo abordado, entre abril de 2007 e dezembro de 2009. Verificamos os sentidos desejados por meio da subjetividade e da intertextualidade, os efeitos de humor e o poder de persuasão do texto chárgico na formação do pensamento, além da relação entre as linguagens verbal e não-verbal. Com isso entendemos que o recurso visual é muito importante na apreensão de sentidos por ser de mais fácil entendimento. Sendo assim, concluímos que a charge é um recurso que consegue transmitir um grande número de informações, com humor e crítica, num pequeno espaço, que se revela rico, humorado e lúdico ao passo que nos instiga a pensar.
\end{abstract}

Palavras-chave: jornalismo; charge; análise do discurso; intertextualidade.

\section{Introdução}

O jornalismo se caracteriza pela imparcialidade, ou seja, a apresentação dos fatos sem a emissão de opinião, mas isso não significa que os jornalistas não façam julgamento sobre as situações. Para contornar essa lacuna da profissão, outros elementos foram introduzidos ao meio jornalístico, como as charges, que funcionam como uma "válvula de escape".

Na maioria das vezes, os chargistas aproveitam um assunto que está em evidência na mídia, por isso a charge dificilmente estará descontextualizada. Vamos encontrar o mesmo assunto sendo

1 Especialista em Língua Portuguesa pelas Faculdades Associadas de Uberaba.

1 Revista (Entre Parênteses) 


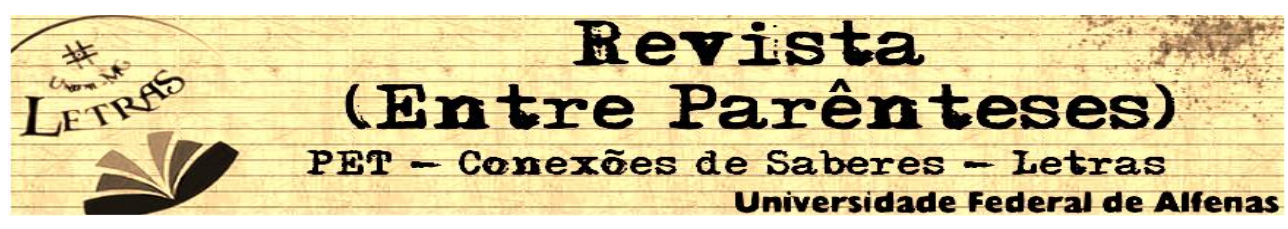

abordado em outras partes do jornal, como um editorial, uma carta do leitor, notícia e, certamente, em outros veículos de comunicação.

O trabalho buscou discutir de que forma as charges expõem a preferência por determinado ponto de vista e como elas podem influenciar no julgamento do cidadão comum. A pesquisa se baseou na análise do discurso, interdiscurso e intertextualidade para avaliação de algumas charges escolhidas aleatoriamente a fim de responder às questões levantadas.

\section{Fundamentação teórica}

A charge é derivada da produção textual, mais especificamente de um gênero textual. Segundo Bakthin (1979), gênero textual é um enunciado de natureza histórica, sociointeracional, ideológica e linguística. $\mathrm{O}$ texto chárgico corresponde a esses quesitos: é de natureza histórica porque é formulado mediante fatos existentes. Também é sociointeracional à medida que interage com a sociedade, fazendo-a pensar e refletir. No que tange à ideologia, também se faz verdadeiro ao discutir ideias e valores que despertam a função social do cidadão de opinar sobre o que acontece ao redor. Possui aspecto linguístico porque reúne as características que os indivíduos usam para se comunicar.

Os gêneros estão em constante evolução. Segundo Cavalcanti (2008, p. 25), "é diante dessa evolução comunicativa que as charges, assim como tantos outros gêneros, surgem e se modificam de acordo com a situação histórico-cultural e com as inovações tecnológicas.".

Para que possamos apreender o conteúdo de uma charge é necessário que façamos uso do conceito do conhecimento prévio. Ele é formado pelo linguístico (que reúne o vocabulário), o textual 


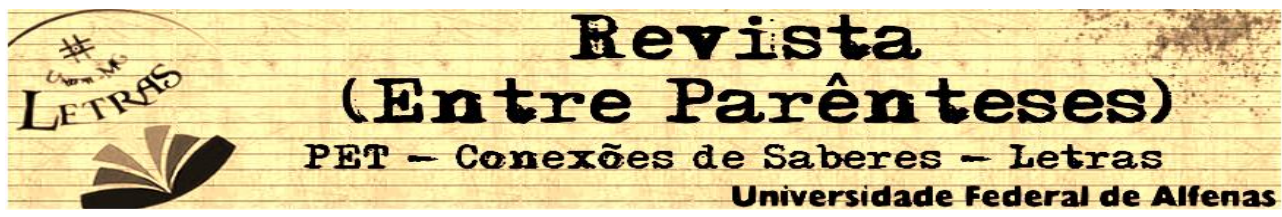

(que compreende os tipos e gêneros textuais - onde se encontra a charge) e o de mundo, baseado naquilo que aprendemos durante a vida, nossas experiências.

\title{
A charge
}

Para Cavalcanti, charge

\begin{abstract}
É a representação gráfica de um assunto conhecido dos leitores segundo a visão crítica do desenhista ou do jornal. Quanto à forma, as charges representam figuras com possibilidades existentes no mundo real. Assim, na maioria delas, são utilizadas caricaturas e símbolos e não desenhos lúdicos, fantasiosos. $\mathrm{Em}$ sua construção, é necessário ter detalhes que forneçam dados suficientes para a compreensão do leitor, tais como a caracterização do ambiente e as marcas simbolizando o tema tratado. (CAVALCANTI, 2008, p. 38).
\end{abstract}

Segundo artigo publicado pela Agência Nacional de Jornais (ANJ, 2007), as primeiras charges surgidas no Brasil criticavam o imperador Dom Pedro II, a corte, as disputas políticas e o modo como o povo brasileiro vivia naquela época. De acordo com Cavalcanti (2008, p. 12), "a charge estaria localizada tanto no domínio humorístico quanto no jornalístico.”.

Para Oliveira e Almeida, o texto chárgico consegue, em um pequeno espaço de desenho, resumir e criticar algum conteúdo relevante invocando a sátira ao expor o fato ao ridículo. Além disso, afirmam que a "charge é crítica porque discute e opina sobre acontecimentos noticiosos, usando para tal uma outra linguagem, a do desenho." (OLIVEIRA; ALMEIDA, 2006, p. 86).

Mas caso as charges não façam o leitor pensar, não terá atingido seu objetivo. Segundo Maringoni (1996, p. 85), elas "só têm função se funcionarem como antenas do jornal, abridores de 


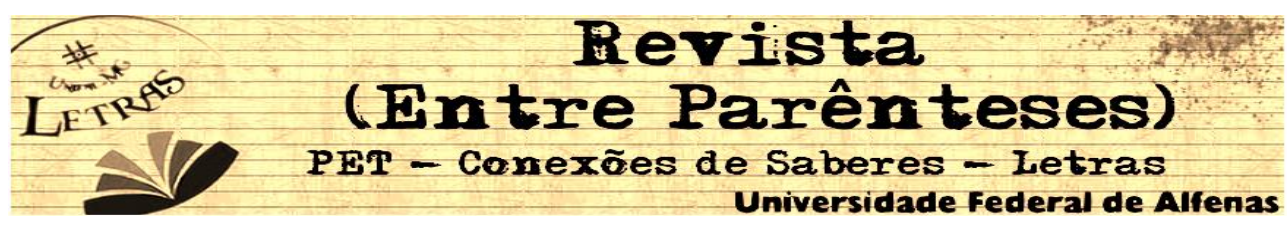

picadas, aventureiros por 'mares nunca dantes navegados' dentro das páginas diárias".

\section{Características da charge}

Segundo Houaiss (2001), a palavra charge deriva do francês e quer dizer carga: "o que exagera o caráter de alguém ou de algo para torná-lo ridículo, representação exagerada e burlesca, caricatura". Essa representação exagerada é a primeira característica que conseguimos identificar numa charge e onde se concentra boa parte do humor, por essa deformação dos traços de forma até agressiva. "Por agressividade entendemos a intencional deformidade dos traços que o exagero imprime. Nesses traços está a refração". (DRIGO; SOUZA; 2006). Ou seja, é a partir dessa desproporção proposital que somos levados a uma mudança de direção de pensamento que até então poderíamos não conhecer ou não havíamos prestado atenção.

As caricaturas são vistas, quase sempre, como algo negativo e que levam a um pré-julgamento. Romualdo (2000, p. 27) diz que ao utilizar do ridículo como recurso a caricatura não apenas faz rir, mas também faz pensar. O leitor acha graça daquilo que fica evidenciado de forma acentuada, mas ele só fará a associação da imagem do caricaturado com a pessoa referida se ele conhecer de quem se trata, por isso, a importância do conhecimento prévio.

O humor é outro ingrediente sempre presente nas charges, mas trata-se de um humor mais carregado, uma sátira que critica uma determinada situação. O chargista, a partir de um determinado assunto, apreende o sentido, compreende como aquilo interfere na vida das pessoas e o transforma com criatividade em outra linguagem que provoca o riso e faz refletir.

A charge, por tratar de assuntos que estão em destaque, tem prazo de validade, ou seja, são temporais. Isso significa que daqui a algum tempo essa mesma charge, que hoje é motivo de 


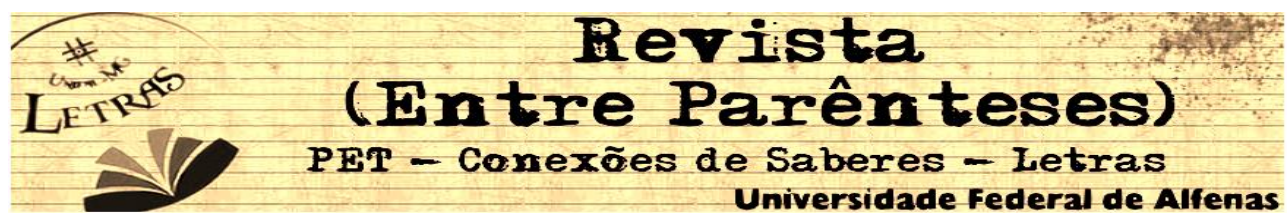

risada, não terá o menor sentido. A fonte está nos fatos que acontecem no dia a dia, nos noticiários, no que é assunto nas rodas de bate papo. Depois que a notícia esfria, a charge perde a graça, o humor não é alcançado e fica sendo apenas um registro, visto que

[...] por causa das transformações constantes que vivem os homens e as sociedades, o contexto social se modifica e, por isso, quando revemos velhas caricaturas ou charges não compreendemos muitas vezes a intenção e o humor desses textos. (ROMUALDO, 2000, p. 42)

Sobre a temporalidade, Drigo e Souza (2006) afirmam que

a charge revela-se como um traço da história, na medida em que capta o ocorrer do processo no seu acontecer. Sintetiza o fato registrando de forma astuciosa e sagaz a imagem do seu tempo, legando às futuras gerações o modo de ver-sentir-pensardeliberar de uma época que o tempo modifica.

Por isso, as charges têm curta duração e o sentido delas logo cai no esquecimento.

O único caso em que o texto chárgico não se perde com o tempo é quando ele é comportamental, ou seja, critica costumes vividos por uma sociedade, como por exemplo, charges sobre portugueses, homossexuais, loiras, etc. Por se tratar de situações estáticas o tempo passa e elas continuam entendíveis e motivo de graça. Maringoni (1996, p. 90) afirma que "Alguns cartunistas conseguem com seu trabalho captar mais o espírito de uma época do que se limitar ao registro do fato do dia. Neste caso, não temos mais a charge política, mas a crítica de costumes e ela adquire uma característica mais duradoura."

Uma das características que leva a charge a ser tão facilmente compreendida é a natureza gráfica. Algumas não precisam de nenhuma palavra para que a mensagem seja 


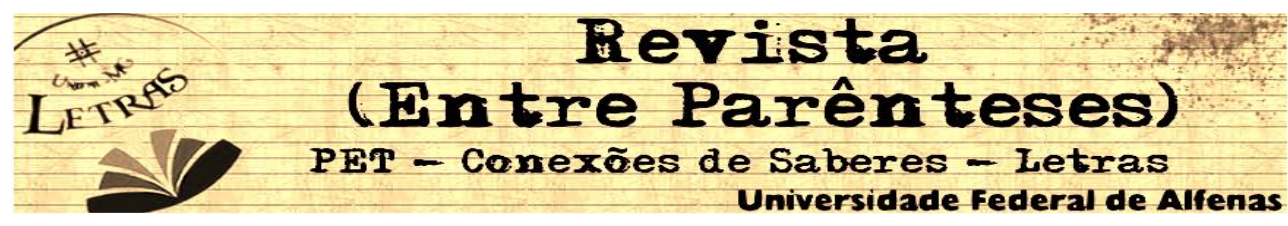

transmitida em face do recurso visual, visto que a "charge jornalística atrai o leitor, pois, enquanto imagem é de rápida leitura, transmitindo múltiplas informações e de forma condensada.". (BRESSANIN, 2006, p. 505).

A intertextualidade é mais um recurso presente na charge. Trata-se da influência de um texto, seja ele um texto verbal, uma figura, ou um gráfico, sobre o outro. Para Orlandi (1996, p. 194) a intertextualidade é algo complexo. Ela afirma que um texto mantém relação com aqueles dos quais ele nasce (matéria-prima) e também com aqueles para onde ele vai (futuro discursivo). Ainda segundo a autora, "os sentidos não estão só nas palavras, nos textos, mas na relação com a exterioridade, nas condições em que eles são produzidos." (2001, p. 30). Por isso, a charge não é considerada como algo solitário, deslocado de outras matérias veiculadas no próprio jornal e em outros produtos.

Sobre esse assunto, Romualdo (2000, p. 2) afirma: "O fato de encontrarmos, em textos veiculados pelo próprio jornal, informações diversas que nos permitam interpretar a charge, mostra que esta mantém relações intertextuais com os outros textos jornalísticos." Ainda segundo este autor, há cinco possibilidades de intertextualidade em relação às charges:

1- A retomada de textos verbais publicados em várias seções, pressupostos no repertório de leitura do interlocutor;

2- Remissão a textos visuais, como a fotografia;

3- Relação simultânea tanto com textos verbais quanto visuais apresentados ou não no jornal;

4- Ligação com a simbologia do dia de publicação (ex. dia dos namorados), indispensáveis para o entendimento da charge;

5- Correlação com outras charges publicadas em dias diferentes, recobrindo um assunto que permanece em pauta durante um certo período. 
Assim, podemos perceber que essa multiplicidade de textos permite a compreensão da charge. O leitor sempre vai buscar alguma informação complementar na memória dele, no próprio jornal ou em outros periódicos para perceber o que o texto chárgico está dizendo. Dessa forma, "ao relacionar a charge com os outros textos do periódico, o leitor recupera a intertextualidade." (ROMUALDO, 2000, p. 86).

Outro ponto importante é em relação ao leitor do texto chárgico e do tipo de leitura obtida. Temos que levar em conta que cada ser pensante tem uma ideia, uma opinião e um conhecimento diferentes. Silva (2000, p. 90) diz que "todo texto apresenta uma unidade possível de significado" justamente por causa da experiência de vida de cada leitor que é importante no momento da interpretação e não pode ser desprezada.

Orlandi (1996) afirma que a leitura é seletiva porque depende das condições e dos objetivos, ou seja, da maneira como essa troca acontece e possibilita os diferentes tipos de leitura. Essa relação não necessariamente se faz com textos veiculados no mesmo dia da charge. Se o leitor acompanha o periódico e o alimento da charge estiver em datas anteriores, ele será capaz de estabelecer essa conexão. 


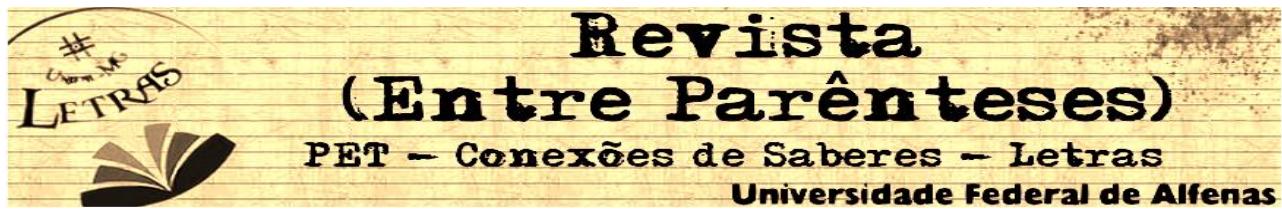

\section{Análise de charges}

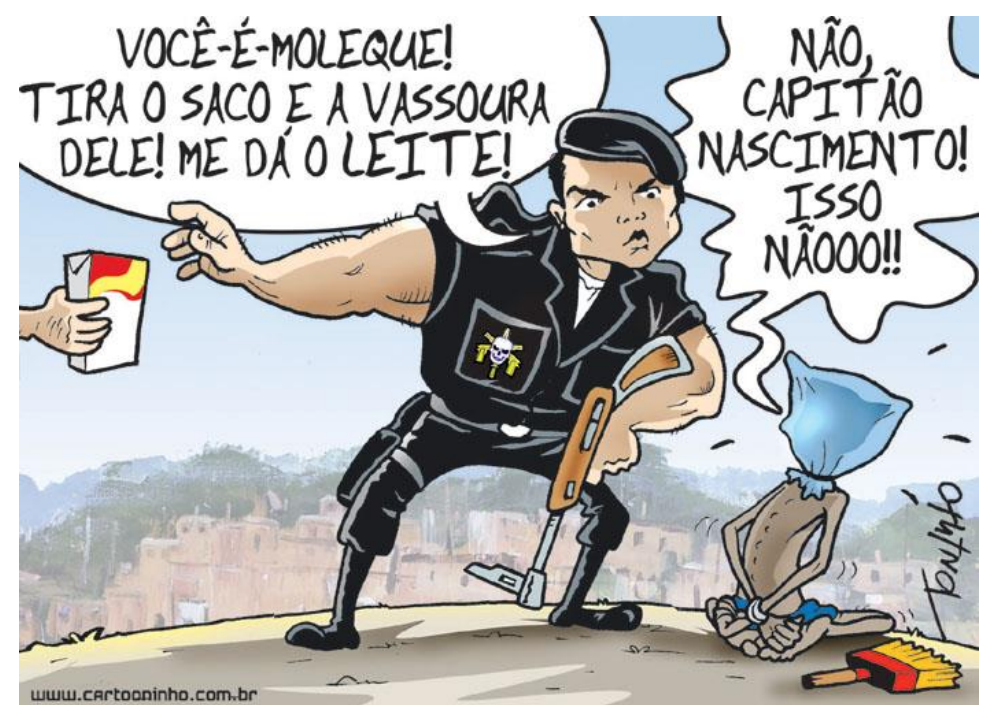

A charge acima, veiculada no dia 14 de novembro de 2007 , no Jornal da Manhã, periódico de Uberaba, traz dois episódios simultaneamente: o escândalo do leite adulterado na cidade e o sucesso do filme brasileiro Tropa de Elite. Para compreendermos melhor o seu sentido, vamos lembrar rapidamente os dois episódios.

O caso do leite ganhou o noticiário no dia 22 de outubro de 2007. A Copervale, indústria responsável pela fabricação de leite e derivados na cidade, foi acusada de ter supostamente adicionado produtos como água oxigenada e soda cáustica ao leite de caixinha para aumentar o volume e garantir maior durabilidade. O escândalo teve repercussão nacional e o produto foi suspenso por um período.

O filme Tropa de Elite foi lançado oficialmente no dia 12 de outubro de 2007 e retrata o dia-a-dia dos policiais do Batalhão de Operações Policiais Especiais (BOPE) do Rio de Janeiro. A história mostra os conflitos entre traficantes e a polícia, o tráfico de drogas e o duro treinamento enfrentado por aqueles que querem entrar para o BOPE, além da tortura aplicada pelos policiais. Em uma das cenas, o capitão Nascimento, interpretado pelo autor Wagner Moura, 


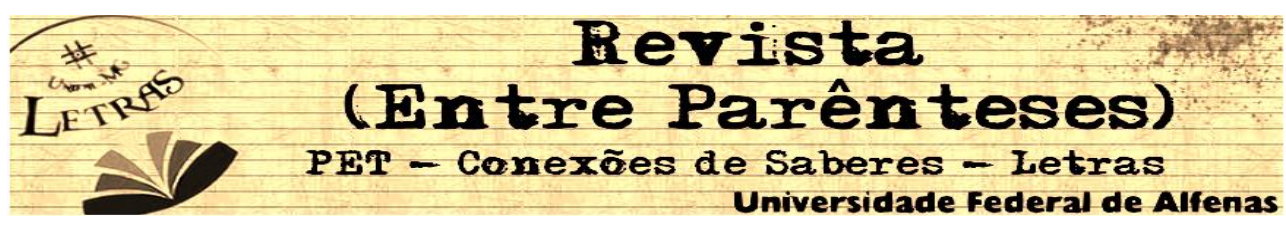

pergunta para um adolescente que faz parte de uma quadrilha onde está o chefe. Como ele se nega a responder, o capitão manda que coloquem um saco na cabeça dele e tragam a vassoura para que o adolescente seja torturado e revele o paradeiro do traficante.

Com essas informações, já é possível fazermos uma análise da charge em questão. Primeiramente, o chargista faz uma paráfrase entre o título do filme (Tropa de Elite) e o título da charge (Tropa de Leite). A caricatura do capitão Nascimento retrata bem a figura do policial: farda, boina, arma e o símbolo do BOPE. Ele está no meio da charge e é muito maior que o garoto e que qualquer outro elemento representado, o que caracteriza sua superioridade.

No lado direito inferior temos a caricatura de um garoto que possivelmente trabalha para o tráfico de drogas. Ele está com as mãos amarradas, tem um saco na cabeça, veste apenas uma bermuda e há um cabo de vassoura ao lado dele. Na cena do filme, enquanto dois homens seguram o menino, o capitão Nascimento pergunta onde está o chefe dele. Como ele diz que não sabe, manda que tragam um saco e a vassoura para dar uma surra nele. $\mathrm{Na}$ charge o garoto já se encontra com o saco na cabeça e o cabo da vassoura por perto. E há uma inversão no castigo: o policial manda que tirem o saco e a vassoura e que tragam o leite, ou seja, o castigo será maior. Isso pode ser confirmado pela frase do garoto: “Não capitão Nascimento! Isso não!!”, o que nos leva a entender que ele preferia levar uma surra com o cabo da vassoura a ter que beber o leite. Quando o policial fala: "Você é moleque!" há uma total conformidade com o filme.

Observa-se a intertextualidade, ou seja, a influência de um texto sobre o outro. Para Orlandi (1996, p. 194), um texto mantém relação com aqueles dos quais ele nasce (matéria-prima) e também com aqueles para onde ele vai (futuro discursivo). Se uma pessoa não tiver assistido ao filme ela dificilmente compreenderá o sentido 


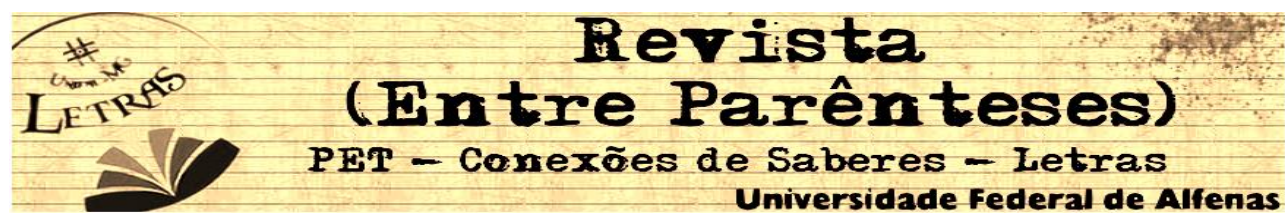

total pretendido pela charge porque algumas informações the faltarão, daí a importância do conhecimento de mundo que adquirimos mediante nossas experiências. Vamos buscar na nossa memória os principais fatos do filme para interpretar o texto chárgico.

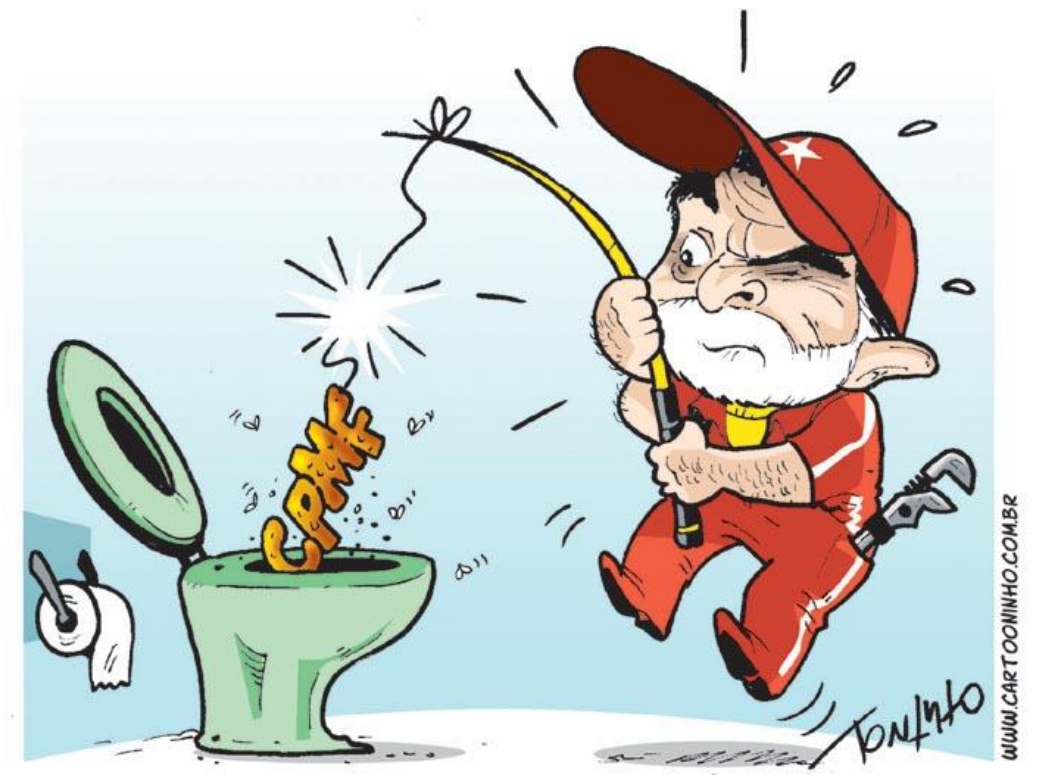

A charge acima, publicada no Jornal da Manhã em 16 de dezembro mostra o presidente Lula vestido como encanador. Sua roupa é vermelha fazendo alusão à cor do Partido dos Trabalhadores (PT) e inclusive, no boné, há o símbolo do partido: uma estrela. Ele também usa uma ferramenta típica deste trabalhador: a chave que está no bolso da calça. Podemos notar que ele faz um esforço enorme ao tentar impedir que a proposta de prorrogar a Contribuição Provisória sobre Movimentação Financeira (CPMF) "vá para o ralo" - em alusão ao desenho do vaso sanitário por causa das gotinhas de suor ao seu redor e de um olho estar fechado, demonstrando o trabalho que ele está tendo, a força que ele está empenhando. Mesmo assim o presidente não consegue a aprovação da CPMF e ela "escapa" quando o Senado derruba a emenda, representada na charge pela corda que se rompe. 


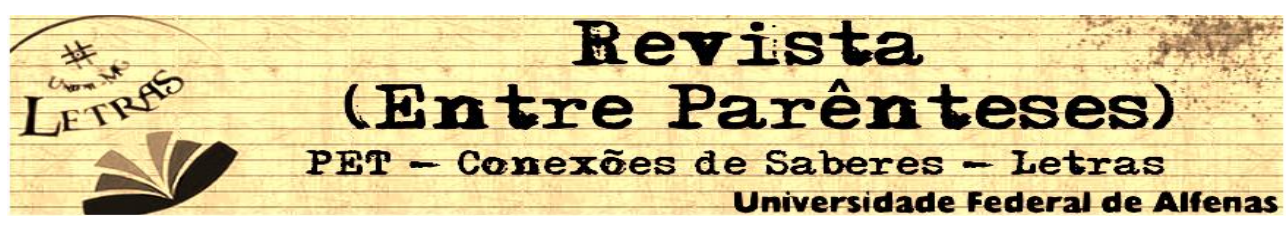

Pudemos constatar o que Romualdo (2000) diz sobre o fato de que muitas charges possam estar relacionadas com textos que foram publicados em outras seções do jornal e também em outros dias e que se pressupõe estar no repertório do leitor. No caso acima, a matéria jornalística foi publicada no dia anterior à charge, mas o assunto ainda estava em evidência. Por isso, o leitor precisa ter o conhecimento prévio e ativá-lo para compreendê-la. Sem esse conjunto fica mais difícil interpretar o que está sendo transmitido através do texto chárgico e chegar às conclusões a respeito do assunto apresentado.

\section{Considerações finais}

Constatamos como a subjetividade está presente nas charges jornalísticas a que nos propomos a analisar. Foi possível identificar como essas informações implícitas e também de duplo sentido ocorrem embutidas na forma de ironia, algumas vezes, para mascarar a crítica apresentada e também como é importante que tenhamos um conhecimento prévio para que possamos inferir esse julgamento e compreender o sentido pretendido.

A análise nos permitiu verificar também a presença da intertextualidade, ou seja, a interferência de outros textos nas charges, principalmente de notícias que também ocorrem nos periódicos e discorrem sobre assuntos semelhantes, geralmente 0 que está em evidência, além de comprovar que o texto chárgico não existe isoladamente.

Foi possível perceber também que a charge é sim um mecanismo formador de opinião porque induz o leitor a refletir a respeito de um determinado assunto e tirar suas próprias conclusões. Mesmo que o chargista exponha o ponto de vista dele, 


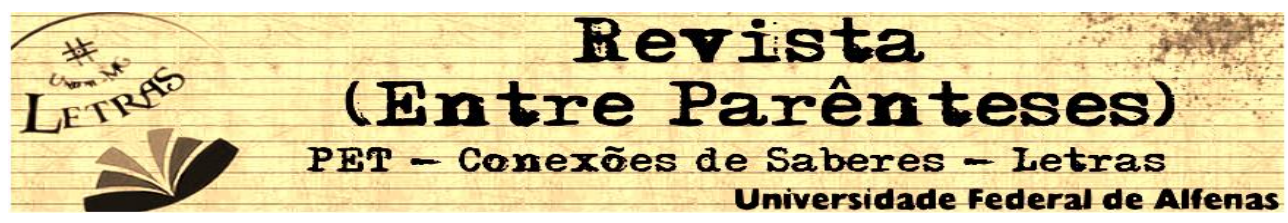

dá margem para outras interpretações, por isso o texto chárgico não tem começo nem fim, mas permite uma infinidade de sentidos que só serão apreendidos a partir das experiências do leitor e do desdobramento dos acontecimentos.

A relação texto/imagem mostra como as duas linguagens verbal e não-verbal - se inter-relacionam na produção do texto chárgico. Além disso, conseguimos verificar como a charge, principalmente através do desenho caricaturado, consegue se fazer mais perceptível aos olhos do leitor e também mais agradável porque condensa várias informações, acompanhadas de crítica e com muito humor num pequeno espaço.

A charge é uma importante fonte de informação e compreender seus efeitos de sentido nos ajudam a entender o mundo em que vivemos, os fatos que acontecem e a elaborar nossas conclusões.

\section{Referências bibliográficas}

ARAGÃO, V. P. S. de. O não-dito construído pelo viés do humor nas charges. 2007. 202 f. Dissertação (Mestrado em Língua Portuguesa). Universidade Federal Fluminense. Niterói, 2007. Disponível em: <http://www.bdtd.ndc.uff.br/tde_arquivos/23/TDE-2007-10-10T143633Z1046/Publico/Dissert-Veronica\%20Aragao.pdf>. Acesso em: 17 dez. 2008.

ASSIS, D. Termos charge e caricatura têm interpretações distintas na história. Disponível em: <http://www1.folha.uol.com.br/folha/ilustrada/ult90u46871.shtml> Acesso em: 14 jul. 2008.

BAKHTIN, M. Os gêneros do discurso. In: Estética da Criação Verbal. São Paulo: Martins Fontes, 1979.

BERGSON. H. O riso: ensaio sobre a significação do cômico. Rio de Janeiro: Zahar. 1983. 


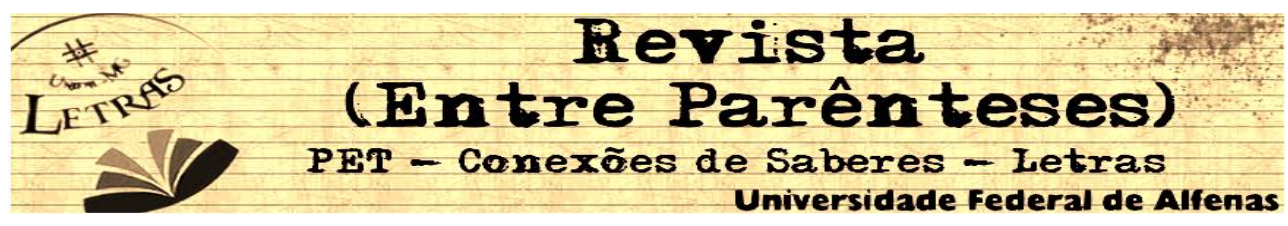

BRESSANIN. A. Gênero charge na sala de aula: o sabor do texto. Universidade Federal de Mato Grosso. 2007. 14 f. Disponível em: $<$ http://linguagem.unisul.br/paginas/ensino/pos/linguagem/cd/Port/8.pdf>. Acesso em 16 jul. 2008.

CAVALCANTI, M. C. C. Multimodalidade e argumentação na charge. 2008. 112 f. Dissertação (Mestrado em Linguística ) - Centro de Artes e Comunicação. Universidade Federal de Pernambuco. Recife, 2008.

Disponível em: <http://www.ufpe.br/pgletras/2008/dissertacoes/diss-Maria-

Clara.pdf>. Acesso em: 21 jan. 2009.

FERNANDES. C. A. Análise do discurso: reflexões introdutórias. São Paulo: Claraluz, 2007.

HOUAISS, Antônio. [Dicionário eletrônico Houaiss da língua portuguesa 1.0]. Edição integral da obra. Editora Objetiva Ltda, 2001.

JORNAL DE UBERABA. Disponível em:

<http://www.jornaldeuberaba.com.br/?MENU=CadernoB\&SUBMENU=Espo rte\&CODIGO=4032>. Acesso em: 23 fev. 2008.

MARINGONI, G. Humor da charge política no jornal. São Paulo: Revista Comunicação e educação, v. 3, n. 7, 2008. Disponível em:

$<$ http://revcom2.portcom.intercom.org.br/index.php/Comedu/article/viewFile /4316/4046.> Acesso em: 15 dez. 2008.

O GLOBO. Disponível em: <http://oglobo.globo.com/opiniao/> Acesso em 18 jul. 2008.

OLIVEIRA, N. A. A. de.; ALMEIDA, L. M. O. Gêneros jornalísticos opinativos de humor: caricaturas e charges. Disponível em: $<$ http://publicacoes.fatea.br/index.php/janus/article/view/38/41>. Acesso em: 23 jan. 2009.

ORLANDI. E. P. A linguagem e seu funcionamento. Campinas: Pontes, 1996.

Análise de discurso: princípios e procedimentos. 3. ed.. Campinas: Pontes, 2001.

ROMUALDO, E. C. Charge jornalística: intertextualidade e polifonia. Maringá: Editora da Universidade Estadual do Maringá, 2000. 


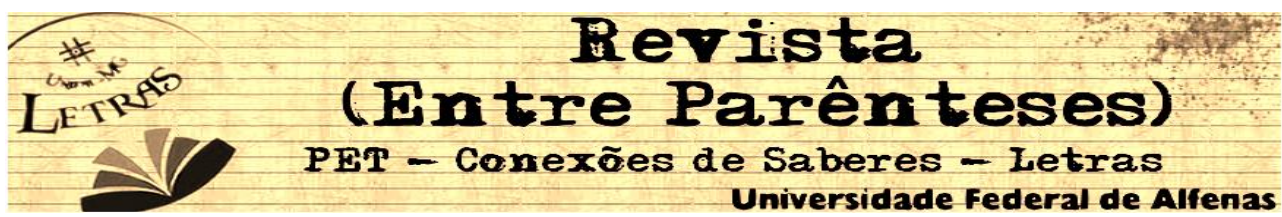

SANTOS, E. P. Gêneros textuais e o discurso das charges: um campo fértil de intertextualidade. Disponível em:

<http://www.webartigos.com/articles/2794/1/generos-textuais-e-o-discursodas-charges/pagina1.html> Acesso em: 26 maio 2008.

SOUZA, L. A. D. Charge jornalística: um passeio pelas estratégias discursivas e pela construção do contrato de comunicação e do sujeitodestinatário nas charges de Angeli/Folha de S. Paulo. 2007. 79f. Monografia (Graduação em Comunicação Social) - Departamento de Ciências da Comunicação - Centro Universitário de Belo Horizonte - UNIBH. 2007. Disponível em:

<http://www.convergencia.jor.br/bancomonos/2007/Leandrodiniz.pdf> Acesso em: 10 jan. 2008.

TÁVORA. A. Pedro Il através da caricatura. Rio de Janeiro: Bloch, 1975.

TROPA DE ELITE. Disponível em: <http://www.tropadeeliteofilme.com.br/>. Acesso em: 16 fev. 2009. 